\title{
Utilizing Soybean Milk to Culture Soybean Pathogens*
}

\author{
Yiwen Xiang ${ }^{1}$, Theresa Herman ${ }^{1}$, Glen L. Hartman, ${ }^{1,2 \#}$ \\ ${ }^{1}$ Department of Crop Sciences, University of Illinois, Urbana, USA \\ ${ }^{2}$ USDA Agricultural Research Service and Department of Crop Sciences, University of Illinois, Urbana, USA \\ Email: " ghartman@illinois.edu
}

Received November 27, 2013; revised December 27, 2013; accepted January 3, 2014

Copyright (C) 2014 Yiwen Xiang et al. This is an open access article distributed under the Creative Commons Attribution License, which permits unrestricted use, distribution, and reproduction in any medium, provided the original work is properly cited. In accordance of the Creative Commons Attribution License all Copyrights (C) 2014 are reserved for SCIRP and the owner of the intellectual property Yiwen Xiang et al. All Copyright (C) 2014 are guarded by law and by SCIRP as a guardian.

\section{ABSTRACT}

Liquid and semi-solid culture media are used to maintain and proliferate bacteria, fungi, and Oomycetes for research in microbiology and plant pathology. In this study, a comparison was made between soybean milk medium, also referred to as soymilk, and media traditionally used for culturing soybean pathogens to determine if soymilk medium was an effective medium for growth of Colletotrichum truncatum, Fusarium virguliforme, Macrophomina phaseolina, Passalora sojina, Phomopsis longicolla, Phytophthora sojae, Pythium irregulare, Rhizoctonia solani, and Sclerotinia sclerotiorum. Based on radial mycelial colony growth rates, $C$. sojina grew significantly $(P<0.05)$ faster on soymilk dextrose agar (SDA) than on $\mathrm{V}-8$ agar, and $C$. truncatum and $F$. virguliforme grew significantly $(P<0.05)$ faster on SDA than potato dextrose agar $(P D A)$. Significantly $(P<0.001)$ greater masses of sclerotia were produced by $S$. sclerotiorum grown on SDA as compared to PDA. Soymilk used with agar or used alone as a broth may be an option for replacing more expensive processed culture media.

\section{KEYWORDS}

\section{Soybean Pathogens; Culture Media; Glycine max}

\section{Introduction}

Culturing microbes dates back to the $19^{\text {th }}$ century when, in 1876, Robert Koch used broths based on fresh beef serum or meat extracts to grow microorganisms [1,2]. Koch also was the first to report on using a solid medium, nutrient gelatin, to obtain pure cultures under a bell jar $[1,3]$. The culturing of microbes has enabled scientific advancements in areas of microbiology, pharmacology, plant pathology, and plant breeding for disease resistance.

There are a number of publications that report on how to culture plant pathogens on various types of growth media. One book widely used in plant pathology is "Plant Pathology Methods" [4] which contains 213 media recipes. Culture media are considered to be either general growth media, in which most cultivatable micro-

\footnotetext{
*Trade and manufacturers' names are necessary to report factually on available data; however, the USDA neither guarantees nor warrants the standard of the product, and the use of the name by USDA implies no approval of the product to the exclusion of others that may also be suitable.

\#Corresponding author.
}

bes grow, or selective media, in which only one or a few microbes grow [4].

The ingredients of culture media, natural or synthetic, along with other factors like light, $\mathrm{pH}$, and temperature will affect the growth of microbes including vegetative growth and production of reproductive (asexual or sexual) structures or other survival structures like sclerotia [5]. Media that are low in nutrient content often increase the sporulation of pathogenic fungi whereas nutrient-rich media often lead to more vegetative growth [4].

Two convenient and widely used commercial products for culturing soybean fungal pathogens are potato dextrose agar (PDA) and potato dextrose broth (PDB). These are powdered commercial media that also can be made from basic ingredients. One liter of PDB contains $24 \mathrm{~g}$ of commercial PDB powder (4 g of potato starch from infusion and $20 \mathrm{~g}$ of dextrose) mixed with $1 \mathrm{~L}$ of water. One L of PDA contains $39 \mathrm{~g}$ of commercial PDA powder (composed of $4 \mathrm{~g}$ potato starch from infusion, $20 \mathrm{~g}$ of dextrose and $15 \mathrm{~g}$ of agar) mixed with $1 \mathrm{~L}$ of water. PDA can also be made by boiling $200 \mathrm{~g}$ of peeled and sliced 
potatoes in $1 \mathrm{~L}$ of water until soft, filtering through cheesecloth, adding 10 to $20 \mathrm{~g}$ of dextrose and 12 to $17 \mathrm{~g}$ of agar before autoclaving [4]. Necrotrophic soybean pathogens listed in the Compendium of Soybean Diseases [6] are able to grow on PDA.

Media other than PDA have been used to induce the formation of certain morphological structures. For example, Fusarium virguliforme produced aerial conidiophores and conidia on synthetic low nutrient agar [7]. Some Fusarium species, including $F$. virguliforme, produced chlamydospores when $10 \mathrm{~mL}$ of sterile distilled water was added to cultures grown on Bilay's medium $[8,9]$. Macrophomina phaseolina was shown to produce abundant pycnidia on peanut butter extract-saturated filter paper placed over soynut butter extract agar [10]. Phytophthora sojae was shown to produce antheridia and oogonia on corn meal, lima bean, and V8 juice agars [11].

Media containing soybean products have been used to culture microbes including plant pathogens. One way to make soy-containing media is to add soybean meal. For example, soybean meal glucose agar was used to enrich and isolate Actinomycetes from soil [4]. Soybean meal agar was used to cultivate and induce oospore production in Phytophthora species by adding 15 g of ground soybean seeds and $20 \mathrm{~g}$ of agar to $1 \mathrm{~L}$ of water without filtering the suspension [4]. Other examples include using tryptic soy medium to support a range of fungal and bacterial growth [12], industrial media "soya bean meal” for tetracycline and streptomycin fermentation [13], and Bacto tryptic soy agar and broth for clinical laboratory use [14]. Formation of microsclerotia of $M$. phaseolina was enhanced by soybean decoction-sucrose medium made by boiling soybean seeds in water and straining them through cheesecloth without grinding [4].

Soymilk has been manufactured as a beverage for many years in Japan and China, but culture media made from soymilk have not been tested for culturing soybean pathogens. Media made from soybean milk could become a cheap substitute for commercially made media for routine culturing of facultative pathogens. In this study, soybean seeds were processed in a soymilk machine to make soymilk. The product from this fast and easy process was used to test the growth of soybean pathogens. The objectives were to 1) evaluate soymilk as a medium, in both broth and agar forms, to grow common soybean pathogens and 2) determine if any morphological structures were altered during growth on and in soymilk based media compared to media commonly used to grow these pathogens.

\section{Materials and Methods}

\subsection{Pathogen Species}

Nine soybean pathogens, Colletotrichum truncatum (Schwein) Andrus \& W.D. Moore, Fusarium virguliforme
(Roy) O’Donnell \& Aoki, Macrophomina phaseolina (Tassi) Goidanich, Passolora sojina (Hara) H. D. Shin \& Braun, Phomopsis longicolla T. W. Hobbs, Phytophthora sojae (Kaufmann \& Gerdemann), Pythium irregulare Buisman, Rhizoctonia solani Kühnand Sclerotinia sclerotiorum (Lib.) de Bary, were used in this study (Table 1). All pathogens were cultured on PDA and PDB media, except $P$. sojina and $P$. sojae, which were maintained on V8 juice agar and V8 juice broth (Philips, 1999; [11]. The pathogens were maintained at $25^{\circ} \mathrm{C}$ and were periodically sub-cultured.

\subsection{Media Preparation}

Soymilk was made in a consumer soymilk maker (Midea, Foshan, China) according to the manufacturers' instructions. Dry seeds (39 g) of cultivar IA 3027, and 1.2 L of water were added to the machine, which produced the milk in 10 minutes after grinding and steaming the seed. The soymilk was poured through a $1-\mathrm{mm}$ diameter strainer. For each liter of soymilk, 20 g of dextrose were added to make soy dextrose broth (SDB). V8 juice broth was prepared by combining $80 \mathrm{~mL}$ of V8 juice, $0.6 \mathrm{~g}$ of CaCO3, $0.2 \mathrm{~g}$ of yeast extract and $1 \mathrm{~g}$ of sucrose in $1 \mathrm{~L}$ of distilled water. PDB was prepared by adding $24 \mathrm{~g}$ of dehydrated PDB (Difco Laboratories, Sparks, MD) to $1 \mathrm{~L}$ of distilled water. Fifteen grams of agar (Becton, Dickinson and Company, Sparks, MD) were added into $1 \mathrm{~L}$ of SDB and V8 juice broth, respectively, to make SDA and V8 juice agar. PDA was prepared by adding $39 \mathrm{~g}$ of dehydrated PDA (Becton, Dickinson and Company) into 1 $\mathrm{L}$ of distilled water. All media were sterilized by autoclaving for $15 \mathrm{~min}$ at $121^{\circ} \mathrm{C}$ and 115 psi. Then the media were cooled to $45^{\circ} \mathrm{C}$ before pouring into 60-mm-diameter sterile plastic Petri dishes at a depth of $5 \mathrm{~mm}$.

\subsection{Macronutrients and Cost Comparisons}

A sample of SDB was lyophilized and tested for carbon, hydrogen and nitrogen percentages and for calcium, potassium, and sodium using the elemental analyses at the Microanalysis Laboratory at University of Illinois (www.scs.illinois.edu/microanalysis/). Each test used 2 mg of lyophilized SDB samples. Economic cost of 1 liter SDB was calculated based on using $39 \mathrm{~g}$ of soybean seeds at a farm price of US \$14 per bushel

(www.farmdoc.illinois.edu) and $20 \mathrm{~g}$ of dextrose at US $\$ 82$ per $500 \mathrm{~g}$ (www.fishersci.com). This was compared to 1 liter of commercial PDB at US \$125 per $500 \mathrm{~g}$ (www.fishersci.com).

\subsection{Growth on Agar Media}

Experiment 1 tested the growth of nine soybean pathogens on SDA. The colony area per day on SDA of all 
Table 1. Soybean pathogens used to compare growth characteristics on soy dextrose agar and broth to growth characteristics on media normally used to culture these pathogens.

\begin{tabular}{|c|c|c|c|c|c|}
\hline Pathogen & Isolate & Origin & Year isolated & Source & Days $^{f}$ \\
\hline Colletotrichum truncatum & IL-15B & Illinois & 2009 & G. L. Hartman ${ }^{\mathrm{a}}$ & 14 \\
\hline Fusarium virguliforme & Mont-1 & Illinois & 1991 & G. L. Hartman & 14 \\
\hline Macrophomina phaseolina & Pinetree & Arkansas & 1998 & J. Rupe ${ }^{\text {b }}$ & 7 \\
\hline Passalora sojina & IL-13-1 & Illinois & 2013 & G. L. Hartman & 9 \\
\hline Phomopsis longicolla & AK100 & Arkansas & 2002 & J. Rupe & 7 \\
\hline Phytophthora sojae & $\mathrm{R} 30$ & Ohio & $-\mathrm{e}$ & A. Dorrance ${ }^{c}$ & 7 \\
\hline Pythium irregulare & SC-R-C23 & Illinois & 2009 & G. L. Hartman & 3 \\
\hline Rhizoctonia solani & Rs1039 & Illinois & - & D. Eastburn ${ }^{\mathrm{a}}$ & 7 \\
\hline Sclerotinia sclerotiorum & Rudd & Iowa & 1996 & J. Q. Liu ${ }^{\mathrm{d}}$ & 7 \\
\hline
\end{tabular}

${ }^{a}$ University of Illinois, Urbana, IL. ${ }^{b}$ University of Arkansas, Fayetteville, AR. 'Ohio State University, Mansfield, OH. ${ }^{\mathrm{d}}$ Pioneer Hi-Bred International, Inc. ${ }^{\mathrm{e}}$ Not known. Incubation days used to test each pathogen.

pathogens was compared to that grown on PDA, except for $P$. sojina and $P$. sojae, for which colony area per day on SDA was compared to rates on V8 juice agar. For each pathogen, a 4-mm diameter mycelial agar plug from the edge of an actively growing culture was transferred onto the center of a 60-mm-diameter agar plate containing PDA, V8 juice agar, or SDA. Cultures were incubated at room temperature in the dark. The number of days required for mycelial growth to reach the edge of a $60 \mathrm{~mm}$-diameter-plate was recorded. The area of the colony was calculated $\left(\mathrm{A}=\pi \times \mathrm{r}^{2}\right)$ and then divided by the number of days. The morphological characteristics of the nine pathogens grown on SDA and traditional media plates were observed at the end of the experiment.

Conidia production of C. truncatum, F. virguliforme, and $P$. sojina, microsclerotia production of M. phaseoli$n a$ and sclerotia production of $S$. sclerotiorum from experiment 1 were quantified. For $F$. virguliforme and $P$. sojina, one 10-mm diameter plug from the outer edge of the culture of each plate of each medium was transferred into a $15-\mathrm{mL}$ centrifuge tube containing $5 \mathrm{~mL}$ sterile $\mathrm{H}_{2} \mathrm{O}$ and shaken using a Vortex mixer (Scientific industries, Inc. Bohemia, NY) for 10 seconds. The procedure was identical for $C$. truncatum except that the $10-\mathrm{mm}$ diameter plug was sampled from near the center of the culture. The number of conidia present on each 10-mm-diameter plug of the three pathogens was estimated by counting conidia with the aid of a hemacytometer under a compound microscope at $20 \times$ magnification. Three plates of each species on each medium were used as three replications of each treatment, and this experiment was repeated once. Microsclerotia produced by M. phaseolina were quantified, with the use of a dissecting microscope at $11.5 \times$ magnification, by cutting a $1 \mathrm{~mm} \times 1 \mathrm{~mm}$ square of agar from the outer edge of each culture plate of each medium; microsclerotia on $1 \mathrm{~mm}$ of the cut-edge surface were counted, and this number for each plate was the experimental unit for statistical analysis. Four plates representing four replications of each treatment were recorded as one trial, and this experiment was repeated once. Sclerotia produced by S. sclerotiorum were harvested 7 days after subculturing and dried in an oven at $38^{\circ} \mathrm{C}$ overnight. The total weight of sclerotia per plate was recorded for statistical analysis. Ten sclerotia were randomly picked from each plate and weighed. The total weight was divided by 10 to get the weight of each sclerotium produced by each plate of both media. Four plates representing four replications of each treatment were recorded as one trial, and this experiment was repeated once.

\subsection{Growth on Liquid Media}

Experiment 2 tested growth of eight soybean pathogens in SDB. Growth in SDB of all pathogens was compared to that on PDB, except for P. sojae, for which growth in SDB was compared to that on V8 juice broth. For each pathogen, five 4-mm-diameter mycelial agar plugs from the edge of an actively growing fungal culture were transferred to $50 \mathrm{~mL}$ of PDB, V8 juice broth or SDB in 250 $\mathrm{mL}$ flasks. Cultures were incubated without shaking at $25^{\circ} \mathrm{C}$ for 3 to 14 days, depending on typical pathogen growth in PDA (Table 1). Broth cultures were filtered through Miracloth (Chicopee Mills, Inc., Milltown, NJ), and the mycelia mass was dried in an oven at $38^{\circ} \mathrm{C}$ for 24 hours. Dry weights of mycelia produced in each flask were recorded. Mycelial dry weight increase of each pathogen grown in SDB was calculated as a percentage, comparing with their growth in traditional media. 


\subsection{Statistical Analysis}

Each experiment was repeated and data from repeated experiments were combined if there was no significant interaction between trials and treatments and if error variances were homogeneous in Bartlett's test for homogeneity. Experiment 1 and 2 consisted of three and four replications, respectively, for each treatment. Analysis of variance (ANOVA) was performed on data from both experiments, and means were separated using Student's t test if the ANOVA was significant. The numbers of conidia produced by $C$. truncatum, $F$. virguliforme, and $P$. sojina, were log 10 transformed after adding 1 to correct for experimental units without conidia before analysis. ANOVA and mean comparisons were performed on the recorded data of quantification of fruiting structure of the four pathogens described above. Data from each repeated experiment were combined for analysis if there was no interaction between trial and fruiting structure quantification. Means were separated using Student's test at $P=$ 0.05 when ANOVA indicated that there were significant differences among them.

\section{Results and Discussion}

\subsection{Growth on Agar Media}

The error variances of the area of colony growth per day of each pathogen were equal from the two trials $(P>$ $0.05)$, and there was no interaction between the trial and treatment variables $(P>0.05)$. Rates of pathogen growth for three of the nine pathogens tested differed between SDA and traditional media (Table 2). Colletotrichum truncatum grew significantly faster $(P<0.001)$ on SDA $\left(4.0 \mathrm{~cm}^{2} /\right.$ day $)$ than on PDA $\left(1.8 \mathrm{~cm}^{2} /\right.$ day $), F$. virguliforme grew significantly faster $(P<0.05)$ on SDA $(1.3$ $\mathrm{cm}^{2} /$ day) than on PDA $\left(0.9 \mathrm{~cm}^{2} /\right.$ day), and $P$. sojina grew significantly faster $(P<0.001)$ on SDA $\left(1.4 \mathrm{~cm}^{2} /\right.$ day $)$ than on V8 juice agar $\left(0.8 \mathrm{~cm}^{2} /\right.$ day). There were no significant differences $(P>0.05)$ between growth rate on SDA and PDA (V-8 juice agar for $P$. sojae) for the other five pathogens, with the average growth on the two media being 7.1, 7.1, 14.1, 7.1, 9.4, and $7.1 \mathrm{~cm}^{2} /$ day for $M$. phaseolina, P. longicolla, P. irregulare, P. sojae, R. solani, and $S$. sclerotiorum, respectively.

There was no significant $(P>0.05)$ interaction between the trial and treatment variables for conidia quantification of $C$. truncatum, $F$. virguliforme, and $P$. sojina, microsclerotia production of $M$. phaseolina and sclerotia production of $S$. sclerotiorum so the data from the two trials were combined. Significant $(P<0.001)$ differences in production of conidia or sclerotia were recorded between the two media for C. truncatum, F. virguliforme, and S. sclerotiorum, but not for M. phaseolina or P. sojina (Table 3). For $C$. truncatum, no conidia were observed on SDA, but counts on PDA were 771,458 con-
Table 2. Analysis of variance for the colony area per day for three soybean pathogens after incubation on different agar media.

\begin{tabular}{ccccc}
\hline Pathogen & Source & DF & F Ratio & Prob $>$ F \\
\hline Colletotrichum truncatum $^{\mathrm{b}}$ & Media & 1 & 214.79 & $<0.0001$ \\
Fusarium virguliforme $^{\mathrm{b}}$ & Media & 1 & 4.97 & 0.0499 \\
Passalora sojina $^{\mathrm{a}}$ & Media & 1 & 21.73 & 0.0009 \\
\hline
\end{tabular}

Table 3. Analysis of variance for conidia and sclerotia production for three soybean pathogens after incubation on potato dextrose agar or soy dextrose agar.

\begin{tabular}{ccccc}
\hline Pathogen & Source & DF & F Ratio & Prob $>$ F \\
\hline Colletotrichum truncatum $^{\text {a }}$ & Media & 1 & 23.48 & 0.0007 \\
Fusarium virguliforme $^{\text {a }}$ & Media & 1 & 63.99 & $<0.0001$ \\
Sclerotinia sclerotiorum $^{\mathrm{b}}$ & Media & 1 & 48.66 & $<0.0001$ \\
\hline
\end{tabular}

${ }^{\mathrm{a}}$ The number of conidia produced by one 10-mm-diaeter plug from cultures grown for 14 days at $25^{\circ} \mathrm{C}$. ${ }^{b}$ Dry sclerotia weights (g) produced by each culture plate were recorded after seven days incubation at $25^{\circ} \mathrm{C}$. Weight per sclerotium produced by $S$. sclerotiorumwas greater when grown in SDA (0.109 per $\mathrm{g}$ for each sclerotium) compared to PDA (0.001 per $\mathrm{g}$ for each sclerotium).

idia/10-mm-diameter plug. Macroconidia produced by $F$. virguliforme were significantly more on PDA $\left(3.6 \times 10^{6}\right.$ conidia/10-mm-diameter plug) than on SDA $\left(1.2 \times 10^{6}\right.$ conidia/10-mm-diameter plug). Total sclerotia weight per plate and weight per sclerotium produced by S. sclerotiorum, were greater when grown in SDA $(0.21 \mathrm{~g}$ sclerotia/plate and 0.109 per $\mathrm{g}$ for each sclerotium) compared to PDA (0.10 g sclerotia/plate and 0.001 per $\mathrm{g}$ for each sclerotium). The cultures of the nine pathogens grown on SDA plates and traditional media plates were presented in Figure 1.

\subsection{Growth on Liquid Media}

In experiment 2, dry mycelial weight from the two trials was combined as variances were equal from the two trials $(P>0.05)$, and there was no interaction between trial and treatment $(P>0.05)$. There was a significant $(P<$ 0.0001 ) effect of media on dry mycelium weight production for all eight pathogens. When using SDB, dry mycelial weights produced by each pathogen more than doubled (least for $F$. virguliforme and greatest for $P$. sojae) compared to weights using the traditional broth media.

\subsection{Macronutrients and Cost Comparisons}

Two mg lyophilized SDB sample was composed of $45 \%$ carbon, 6\% hydrogen, 3\% nitrogen, $0.094 \%$ calcium, $1.377 \%$ potassium and $0.002 \%$ sodium. The cost of 1 liter of SDB was US $\$ 3.29$, while the cost of commercial PDB was US \$5.98. The cost of SDB could be further 
Colletotrichum truncatum
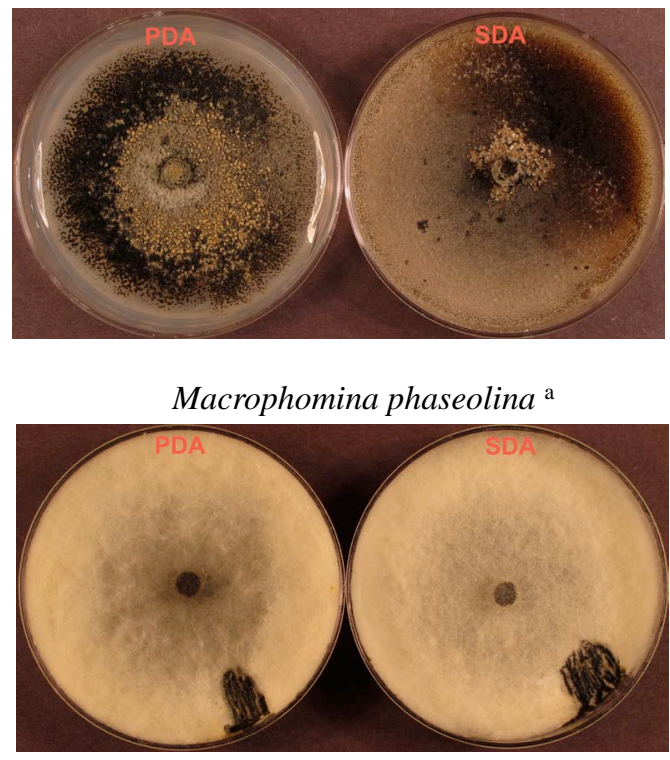

Phomopsis longicolla

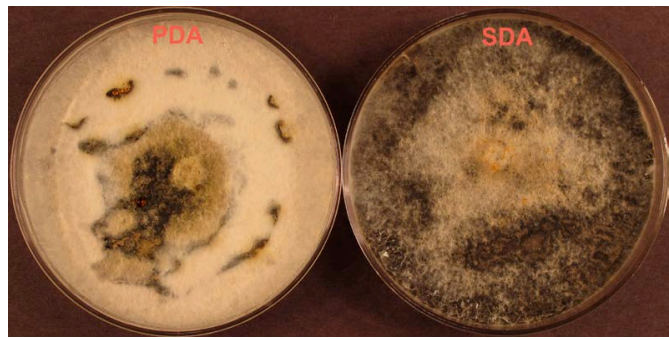

Pythiumirregulare

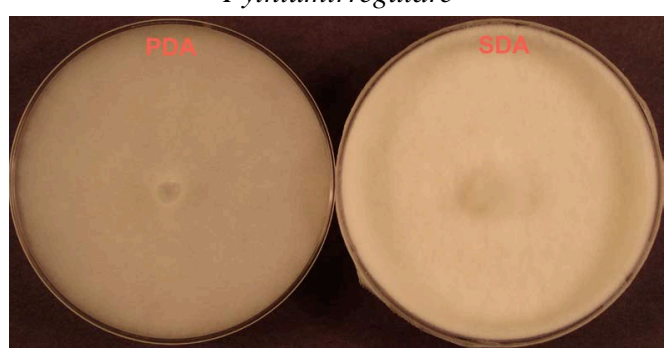

Fusarium virguliforme

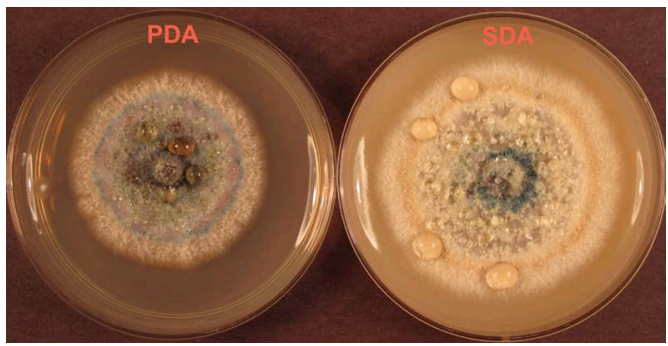

Passalora sojina

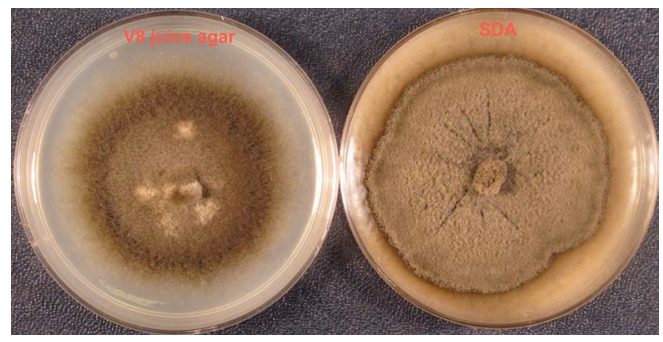

Phytophthora sojae

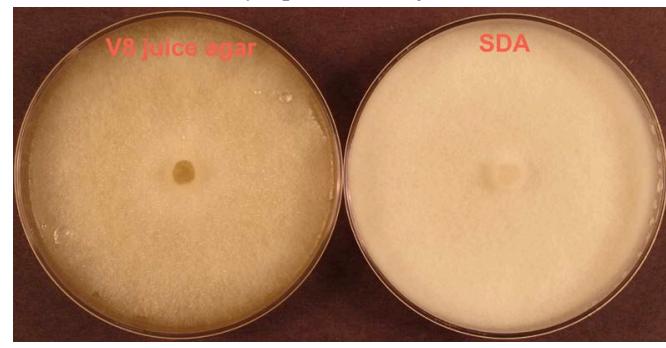

Rhizoctonia solani

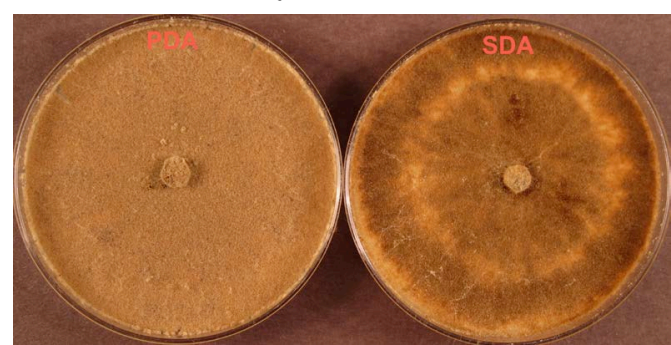

Sclerotinia sclerotiorum

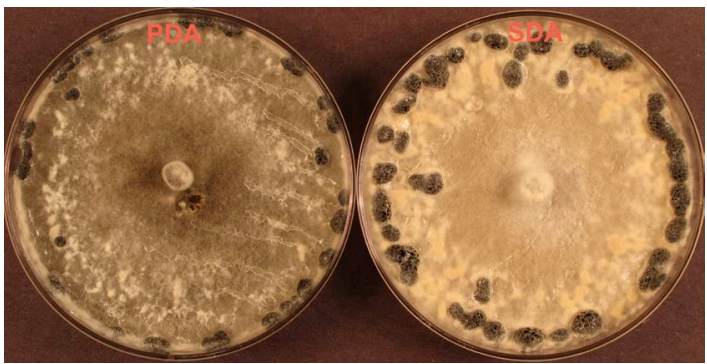

Figure 1. Morphological characteristics of nine soybean pathogens growing on soy dextrose agar (SDA) and traditional agar

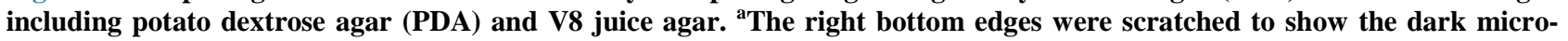
sclerotia under white mycelia 
reduced without dextrose.

Along with its use as a general growth medium, SDB has other advantages over PDB. First, quantity of raw materials are less to make SDB compared to PDB, which leads to lower costs. Second, soybean seeds are available around the world and can be stored for up to 13 to 15 years without concomitant deterioration in quality if stored properly [15]. Although aged soybean seeds were not tested in our experiment to determine if microbial growth differed between freshly harvested and aged seeds, it is likely that even aged seeds would provide growth of the tested pathogens on soymilk. Third, the SDB preparation procedure may be simplified by skipping the autoclave step, because soymilk from the soymilk machine was sterile when tested several times by adding $1 \mathrm{~mL}$ samples of the soymilk to PDA medium without autoclaving. Mereover, it should be easy to industrialize the process of using soybean seeds for culture media production. Just like dehydrated PDA powder manufactured by the Difco Lab [14], there are studies on producing instant soymilk powder by ultrafiltration, spray drying, and fluidized bed agglomeration [16]. These same processes could be used to industrialize soymilk powder for culture media production.

Using soymilk in media has some limitations. Sporulation of $C$. truncatum and $F$. virguliforme on SDA was significantly lower than on PDA, despite the abundance of vegetative growth. Previous publications indicated conidia of $C$. truncatum could be produced in a media with total carbon concentration of $4 \mathrm{~g} / \mathrm{L}$ and carbon/nitrogen ratio of $40: 1,15: 1$ and 5:1 [17]. In this experiment, the SDB was made with total carbon concentration of $12 \mathrm{~g} / \mathrm{L}$ and carbon/nitrogen ratio of $13: 1$ according to the $\mathrm{CHN}$ analysis. The higher carbon concentration might be the main reason for the poor sporulation. Accordingly, diluting the concentration of soymilk or reducing the amount of dextrose may increase the sporulation of $C$. truncatum.

Future studies need to explore more potential uses of soymilk in culturing microbes. This could include studies on soymilk concentration in medium and how that affects fungal growth and reproduction, and to determine if soymilk could be used to culture a wide range of microbes including those used as biological control agents, where cheap growth media may be of interest. In addition, the use of soymilk broth could be used in growing those pathogens/isolates that do not readily produce spores on traditional media. Once grown on soymilk broth, the mycelia can be fragmented, quantified, and used to inoculate plants for studies focused on evaluating plants for resistance or for comparing virulence of isolates.

\section{Conclusion}

In conclusion, a medium made from soybean milk, also referred to as soymilk, was an effective medium for growth of all the facultative soybean pathogens tested. Soymilk used with agar or used alone as a broth may be a viable substitute to replace more expensive processed media. This is the first report of using soybean milk obtained from a soybean milk making machine.

\section{Acknowledgements}

We would like to thank Jess Stewart for her general review of this manuscript and to the North Central Soybean Research Board and the United Soybean Research Board for partial support of this research.

\section{REFERENCES}

[1] R. Koch, "Zur Untersuchung von Pathogenen Organismen,” Mitthdungen uus dem Kaiserlichen Gesundbeitsamte, Vol. 1, No. 1, 1881, pp. 1-48.

[2] T. D. Brock, "The Etiology of Anthrax, Based on the Life History of Bacillus anthracis,” In: T. D. Brock, Ed., Milestones in Microbiology 1556 to 1940, ASM Press, Washington DC, 1999, pp. 89-95.

[3] T. D. Brock, "Methods for the Study of Pathogenic Organisms,” In: T. D. Brock, Ed., Milestones in Microbiology 1556 to 1940, ASM Press, Washington DC, 1999, pp. 101108.

[4] O. D. Dhingra and J. B. Sinclair, "Basic Plant Pathology Methods,” CRC Press, Boca Raton, 1985.

[5] O. D. Dhingra and J. B. Sinclair, "Culture of Pathogens," Basic Plant Pathology Methods, CRC Press, Boca Raton, 1985, pp. 11-47.

[6] G. L. Hartman, J. B. Sinclair and J. C. Rupe, "Compendium of Soybean Diseases,” 4th Edition, American Phytopathological Press, St. Paul, Minn., 1999.

[7] T. Aoki, K. O’Donnell, Y. Homma and A. R. Lattanzi, "Sudden-Death Syndrome of Soybean Is Caused by Two Morphologically and Phylogenetically Distinct Species within the Fusarium solani Species Complex-F. virguliforme in North America and F. tucumani," Mycologia, Vol. 95, No. 4, 2001, pp. 660-684.

http://dx.doi.org/10.2307/3761942

[8] C. Booth, "Methods of Isolation, Culture and Stimulation of Sporulation,” In: Kew, Ed., The Genus Fusarium, Easter Press, Surrey, 1971, pp. 21-23.

[9] S. Li, G. Hartman and L. Gray, "Chlamydospore Formation, Production, and Nuclear Status in Fusarium solani f. sp. glycines Soybean Sudden Death Syndrome-Causing Isolates,” Mycologia, Vol. 90, No. 3, 1998, pp. 414-421. http://dx.doi.org/10.2307/3761400

[10] J. Ma, C. B. Hill and G. L. Hartman, "Production of Macrophomina phaseolina Conidia by Multiple Soybean Isolates in Culture," Plant Disease, Vol. 94, No. 9, 2011, pp. 1088-1092. http://dx.doi.org/10.1094/PDIS-94-9-1088

[11] A. F. Schmitthenner, "Phytophthora Rot,” In: G. L. Hartman, J. B. Sinclair and J. C. Rupe, Eds., Compendium of Soybean Diseases, American Phytopathological Press, St. Paul, Minn., 1999, pp. 46-47.

[12] D. Cleland, K. Jastrzembski, E. Stamenova, J. Benson, C. 
Catranis, D. Emerson and B. Beck, "Growth Characteristics of Microorganisms on Commercially Available Animal-Free Alternatives to Tryptic Soy Medium,” Journal of Microbiological Methods, Vol. 69, No. 2, 2007, pp. 345-352. http://dx.doi.org/10.1016/j.mimet.2007.02.004

[13] N. Okafor, "Industrial Media and the Nutrition of Industrial Organisms,” In: N. H. Enfield, Ed., Modern Industrial Microbiology and Biotechnology, Science Publishers, 2007, pp. 54-76.

[14] Anonymous, "Product Descriptions,” In: D. Laboratories, Ed., Difco Manual of Dehydrated Culture Media and Reagents for Microbiological, 10th Edition, Difco Laboratories, Detroit, 1984, pp. 55-1145.

[15] W. Q. Sun and A. C. Leopold, “Glassy State and Seed Sto- rage Stability: A Viability Equation Analysis,” Annals of Botany, Vol. 74, No. 6, 1994, pp. 601-604. http://dx.doi.org/10.1006/anbo.1994.1160

[16] N. Jinapong, M. Suphantharika and P. Jamnong, "Production of Instant Soymilk Powders by Ultrafiltration, Spray Drying and Fluidized Bed Agglomeration," Journal of Food Engineering, Vol. 84, No. 2, 2008, pp. 194-205. http://dx.doi.org/10.1016/j.jfoodeng.2007.04.032

[17] M. A. Jackson, R. J. Bothast and D. A. Schisler, "Influence of Nutrition during Conidiation of Colletotrichum truncatumon Conidial Germination and Efficacy in Inciting Disease in Sesbania exaltata," Phytopathology, Vol. 81, No. 6, 1991, pp. 587-590.

http://dx.doi.org/10.1094/Phyto-81-587 